\title{
Surface displaced alfa-enolase of Lactobacillus plantarum is a fibronectin binding protein
}

\author{
Cristiana Castaldo ${ }^{1}$, Valeria Vastano ${ }^{1}$, Rosa Anna Siciliano ${ }^{2}$, Marco Candela ${ }^{3}$, \\ Manuela Vici ${ }^{4}$, Lidia Muscariello ${ }^{1}$, Rosangela Marasco ${ }^{5}$ and \\ Margherita Sacco*1
}

Address: ${ }^{1}$ Dipartimento di Scienze Ambientali, Seconda Università di Napoli, via Vivaldi 43, 81100 Caserta, Italy, ${ }^{2}$ Centro di Spettrometria di Massa Proteomica e Biomolecolare, Istituto di Scienze dell'Alimentazione, CNR, Avellino, Italy, ${ }^{3}$ Dipartimento di Scienze Farmaceutiche, Università di Bologna, via Belmeloro 6, 40126 Bologna, Italy, ${ }^{4}$ Dipartimento di Patologia Sperimentale, Università di Bologna, via S. Giacomo 14 , 40126 Bologna, Italy and ${ }^{5}$ Dipartimento di Scienze della Vita, Seconda Università di Napoli, via Vivaldi 43, 81100 Caserta, Italy

Email: Cristiana Castaldo - ccastaldo@sienabiotech.it; Valeria Vastano - valeria.vastano@unina2.it; Rosa Anna Siciliano - rsiciliano@isa.cnr.it; Marco Candela - marco.candela@unibo.it; Manuela Vici - manuela.vici@unibo.it; Lidia Muscariello - lidia.muscariello@unina2.it; Rosangela Marasco - rosangela.marasco@unina2.it; Margherita Sacco* - margherita.sacco@unina2.it

* Corresponding author

Published: 16 February 2009

Microbial Cell Factories 2009, 8:14 doi:10.1 186/1475-2859-8-14
Received: 12 January 2009

Accepted: 16 February 2009

This article is available from: http://www.microbialcellfactories.com/content/8/1/14

(C) 2009 Castaldo et al; licensee BioMed Central Ltd.

This is an Open Access article distributed under the terms of the Creative Commons Attribution License (http://creativecommons.org/licenses/by/2.0), which permits unrestricted use, distribution, and reproduction in any medium, provided the original work is properly cited.

\begin{abstract}
Background: Lactic acid bacteria of the genus Lactobacillus and Bifidobacterium are one of the most important health promoting groups of the human intestinal microbiota. Their protective role within the gut consists in out competing invading pathogens for ecological niches and metabolic substrates. Among the features necessary to provide health benefits, commensal microorganisms must have the ability to adhere to human intestinal cells and consequently to colonize the gut. Studies on mechanisms mediating adhesion of lactobacilli to human intestinal cells showed that factors involved in the interaction vary mostly among different species and strains, mainly regarding interaction between bacterial adhesins and extracellular matrix or mucus proteins. We have investigated the adhesive properties of Lactobacillus plantarum, a member of the human microbiota of healthy individuals.
\end{abstract}

Results: We show the identification of a Lactobacillus plantarum LM3 cell surface protein ( $48 \mathrm{kDa})$, which specifically binds to human fibronectin $(\mathrm{Fn})$, an extracellular matrix protein. By means of mass spectrometric analysis this protein was identified as the product of the L. plantarum enoAl gene, coding the EnoAI alfa-enolase. Surface localization of EnoAI was proved by immune electron microscopy. In the mutant strain $\mathrm{LM} 3-\mathrm{CCl}$, carrying the enoAl null mutation, the $48 \mathrm{kDa}$ adhesin was not anymore detectable neither by anti-enolase Western blot nor by Fn-overlay immunoblotting assay. Moreover, by an adhesion assay we show that LM3-CCI cells bind to fibronectin-coated surfaces less efficiently than wild type cells, thus demonstrating the significance of the surface displaced EnoAI protein for the L. plantarum LM3 adhesion to fibronectin.

Conclusion: Adhesion to host tissues represents a crucial early step in the colonization process of either pathogens or commensal bacteria. We demonstrated the involvement of the L. plantarum Eno Al alfa-enolase in Fn-binding, by studying LM3 and LM3-CCI surface proteins. Isolation of LM3-CCI strain was possible for the presence of expressed enoA2 gene in the L. plantarum genome, giving the possibility, for the first time to our knowledge, to quantitatively compare adhesion of wild type and mutant strain, and to assess doubtless the role of $L$. plantarum Eno Al as a fibronectin binding protein. 


\section{Background}

The role of a balanced human gut microbiota is crucial in host health, representing a protection against disease and a support for efficient and healthy gut function [1-3]. The microbial species composition varies along the length of the gut, and it is influenced by diet, environment, and aging [4]. The protective role of commensal bacteria within the gut consists in outcompeting invading pathogens for ecological niches and metabolic substrates [5,6]. In particular, some indigenous bacteria are believed to have the ability to overcome pathogens by producing acids, bacteriocins or hydrogen peroxide. Moreover, it is now believed that interference with pathogen adhesion could be a powerful way of preventing infection [7]. The gut microbiota represents also an important modulator of the immune system, educating the infant immune system, and being a source of non-inflammatory immune stimulators in healthy individuals $[8,9]$.

Lactic acid bacteria (LAB) of the genus Lactobacillus and Bifidobacterium are one of the most important health promoting groups of the human intestinal microbiota. Traditionally present in the dairy products, such microorganisms have been used for treatment and prevention of gut diseases since long time ago, and more recently the beneficial effects of some probiotic LAB strains were assessed by clinical trials [7]. Specific probiotic LAB strains were also shown to modulate the host immune system and to reduce allergic symptoms. For these reasons they are considered good live vectors for vaccine delivery $[10,11]$.

Lactobacillus plantarum is a member of the human microbiota of healthy individuals [12]. Due to its metabolic versatility, and to its strong ability to preserve food and prevent spoilage, L. plantarum has been largely used as starter in food industry and for the development of probiotic food $[13,14]$. The probiotic features of many strains of $L$. plantarum have been extensively studied and well assessed. Among the features necessary to provide health benefits, probiotic microorganisms must have the ability to adhere to human intestinal cells and consequently to colonize the gut. Some strains of $L$. plantarum have been positively tested for their ability to adhere to human colonic cell lines, to survive gastrointestinal passage and to persist in the intestine of healthy volunteers after oral administration [15-17].

Pathogen and commensal bacteria have evolved many mechanisms functional to a successful colonization of the host gut: rapid multiplication, expression of adhesins, and the use of non-specific adhesion mechanism like hydrophobicity, electrostatic interactions and protective capsules [18]. Studies on mechanisms mediating adhesion of lactobacilli to human intestinal cells showed that factors involved in the interaction vary mostly among different species and strains, mainly regarding interaction between bacterial adhesins and extracellular matrix (ECM) or mucus proteins $[19,20]$. Adhesion of L. plantarum to human intestinal cell line HT-29 is mediated by a mannose-specific adherence mechanism [21,22]. This kind of adherence mechanism is common among Gram-negative bacteria, but rare for Gram-positive. This could be the reason for the ability of L. plantarum to compete with potentially pathogenic microorganisms for receptors on the surface of human intestinal ECM. The mannose specific adhesin Msa of L. plantarum has been identified by in silico matching of genotypic and phenotypic characteristics of $L$. plantarum strains showing positive or negative mannose adhesion capability [23]. In the L. plantarum WCFS1 genome sequence, the corresponding msa gene was annotated as a gene coding a putative cell surface protein, supporting the finding that the Msa protein is an adhesin [24].

Fibronectin (Fn) is an ECM protein shown to be involved in the bacteria-endothelial cell interaction and several Fnbinding proteins have been identified in Gram positive bacteria. The aim of this study was the characterization of Fn-binding proteins in the adhesive probiotic species $L$. plantarum. In our study we selected the L. plantarum LM3 strain, previously classified as a mannose adhesive strain [23].

\section{Results}

Identification of L. plantarum Fn-binding surface proteins We classified the L. plantarum LM3 as an adhesive strain, according to Jacobsen and coworkers [25], by binding assay performed on Caco- 2 cells. To identify putative bacterial adhesins, we performed immunoblot overlay assays of LM3 surface proteins with human fibronectin. The LM3 surface proteins were extracted, separated by SDS-PAGE, blotted onto a PVDF membrane, and tested for fibronectin binding. Two signals, corresponding to proteins with an apparent molecular mass of $40 \mathrm{kDa}$ and $48 \mathrm{kDa}$, were detected (Fig. 1). The putative fibronectin binding proteins were subjected to in-gel tryptic digestion and analyzed by MALDI-TOF mass spectrometry. Protein identification was achieved by database searches using the Mascot search program. Results are listed in Table 1. The MALDI-TOF-MS analysis performed on the $40 \mathrm{kDa}$ putative adhesin of the LM3 strain revealed that the band contained five co-migrating proteins: D-alanyl transfer protein DltD; GTP cyclohydrolase II; oligopeptide ABC transporter, ATP-binding protein; alfa-subunit of the E1 component of the pyruvate dehydrogenase complex; ATPbinding protein of the glycine betaine/carnitine/choline $\mathrm{ABC}$ transporter (Table 1). The $48 \mathrm{kDa}$ protein was identified as the L. plantarum WCFS1 enoA1 gene product, namely the phosphopyruvate hydratase or alfa-enolase 
Table I: Identification of fibronectin binding proteins by MALDI-TOF-MS analysis.

\begin{tabular}{|c|c|c|c|c|}
\hline Sample & Acc. N. & Protein & $\mathrm{MW}(\mathrm{kDa})$ & Gene \\
\hline $\begin{array}{l}\text { Band A } \\
(48 \mathrm{kDa})\end{array}$ & Gl_28377645 & $\begin{array}{l}\text { Phosphopyruvate hydratase } \\
\text { (enolase) }\end{array}$ & 48,057 & enoAl \\
\hline \multirow[t]{5}{*}{$\begin{array}{l}\text { Band B } \\
(40 \mathrm{kDa})\end{array}$} & GI_2837865 I & $\begin{array}{l}\text { D-alanyl transfer protein } \\
\text { DltD }\end{array}$ & 48,633 & $d l t D$ \\
\hline & GI_28378I56 & GTP cyclohydrolase II & 43,873 & ribA \\
\hline & Gl_28378767 & Pyruvate dehydrogenase complex, EI component, alfa subunit & $4 \mid, 443$ & $\operatorname{pdh} A$ \\
\hline & Gl_28378030 & Oligopeptide $A B C$ transporter, ATP-binding protein & 39,760 & oppD \\
\hline & GI_28378307 & $\begin{array}{l}\text { Glycine betaine/carnitine/choline } \\
\text { ABC transporter, ATP-binding } \\
\text { protein }\end{array}$ & 44,505 & opuA \\
\hline
\end{tabular}

(EnoA1). A database search in the L. plantarum WCFS1 genome, a strain showing a high identity percentage with the LM3 genome [26], showed that enoA1 is the last gene of the pentacistronic $c g g R$ operon containing genes encoding the central glycolytic enzymes [24].

\section{Sub-cellular localization of the $L$. plantarum alfa-enolase} To prove the surface localization of the EnoA1 protein, immune electron microscopy experiments were performed on whole L. plantarum LM3 cells, using an antienolase polyclonal antibody generated against the Streptococcus pneumoniae alfa-enolase, sharing $71 \%$ identity with the EnoA1 protein. Bacterial cells were incubated with anti-enolase antibody, then treated with secondary antibody conjugated with $10 \mathrm{~nm}$-colloidal gold particles and

(A)

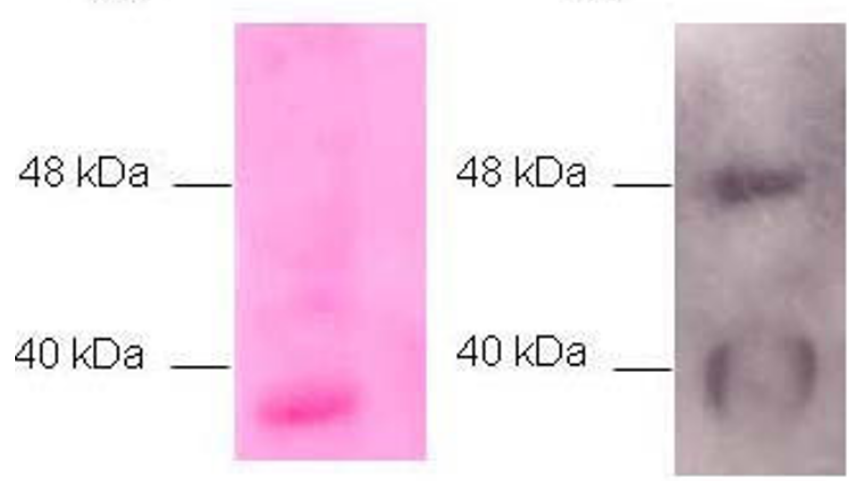

Figure I

Identification of Fn-binding surface proteins of $L$. plantarum LM3. (A) PVDF membrane stained with Ponceau S. (B) Autoradiography of PVDF membrane after peroxidase assay. embedded in Araldite $M$ resin. The pellets were sliced using an ultramicrotome and observed by a scanning electron microscope. Electron microscopy observation revealed the presence of gold particles on the surface of $L$. plantarum LM3 cells, thus indicating the presence of a alfaenolase on the cell wall of whole cells (Fig. 2).

\section{Isolation of the LM3-CCI strain}

The L. plantarum WCFS1 genome, sharing high percent of sequence identity with the LM3 strain [26], is characterized by the presence of two genes (lp_0792 and lp_1920)

(A)

(B)
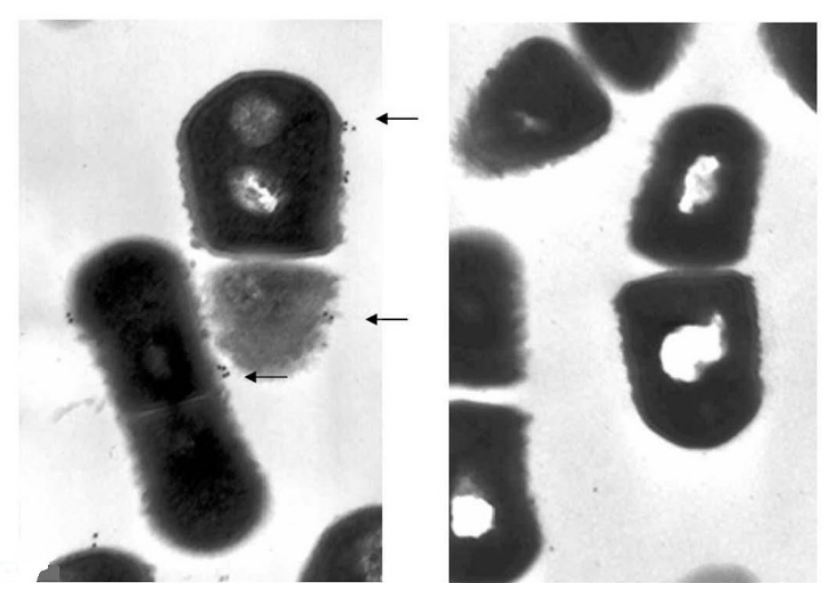

Figure 2

Immunogold staining of enolase on L. plantarum LM3 thin sections. The enolase was detected on the bacterial surface by anti-Eno antibodies and $10 \mathrm{~nm}$-colloidal goldlabeled secondary antibody. LM3 with (A) and without (B) primary antibody. The $10-\mathrm{nm}$ gold particles are indicated by the arrows. 
encoding for two putative proteins with predicted alfaenolase activity [24]. Both genes, named enoA1 and enoA2, are expressed in L. plantarum LM3 under standard growth conditions as detected by microarray analysis (Muscariello, personal comunication). The enoA1 gene belongs to the so-called "central glycolytic genes operon" ( $\operatorname{cgg} R)$, and is located at the 3' end of the operon [24]. The presence of two expressed eno genes allowed the isolation of a $L$. plantarum strain carrying a null mutation in the enoA1 gene, by a double-step homologous recombination process. The entire enoA1 coding region, with the exception of the first $109 \mathrm{bp}$, was replaced by a DNA fragment carrying the ery antibiotic resistance cassette. Sixteen percent of the recombinant clones analyzed showed that a double homologous recombination event had occurred, as detected by PCR analysis. One of these clones, hereby named LM3-CC1, showing a doubling time comparable to its isogenic wild type strain, was chosen for further analysis.

\section{Transcriptional analysis of the cggR operon in the LM3- CCI strain}

In order to verify transcription of the $c g g R$ operon in the mutant strain, a primer extension analysis was performed on total transcripts extracted from LM3 and LM3-CC1 strains. No difference was detected in the two strains, as measured by PhosphorImager (Fig. 3, panel A), showing that replacement of the enoA1 gene with the ery antibiotic resistance cassette did not affect transcription of the operon. To further analyze the effect of the enoA1 gene deletion on transcription of the $c g g R$ operon, Northern blot analysis was performed on total RNA extracted from both strains. A 360-bp fragment internal to the $c g g R$ gene, the first gene of the pentacistronic operon, was used as a probe. A signal of about $5.7 \mathrm{~kb}$, corresponding to transcripts from the entire $c g g R$ operon, was observed in both LM3 and LM3-CC1 strains (Fig. 3, panel B). The difference of calculated size between $c g g R$ transcripts from the wildtype and the mutant strain, less than $200 \mathrm{bp}$, is likely to be undetectable on a $1 \%$ agarose gel. When a different probe was used (320-bp fragment internal to the enoA1 gene), the $5.7 \mathrm{~kb}$ signal was observed in the LM3 strain, whereas no signal was detected in the LM3-CC1 strain (Fig. 3, panel C).

\section{Analysis of the LM3-CCI cell surface proteins}

Surface proteins extracted from wild type and LM3-CC1 cells were resolved by two dimensional electrophoresis, and western blotted by using the anti-enolase polyclonal antibody generated against the Streptococcus pneumoniae alfa-enolase. In the wild type strain the presence of two proteins, showing molecular mass of 48 and $46,6 \mathrm{kDa}$, and $\mathrm{pI}$ of 4,6 and 4,9 respectively, was detected (Fig. 4, panel A), corresponding to EnoA1 and EnoA2 as reported in Swiss-Prot data base. The same analysis, performed on

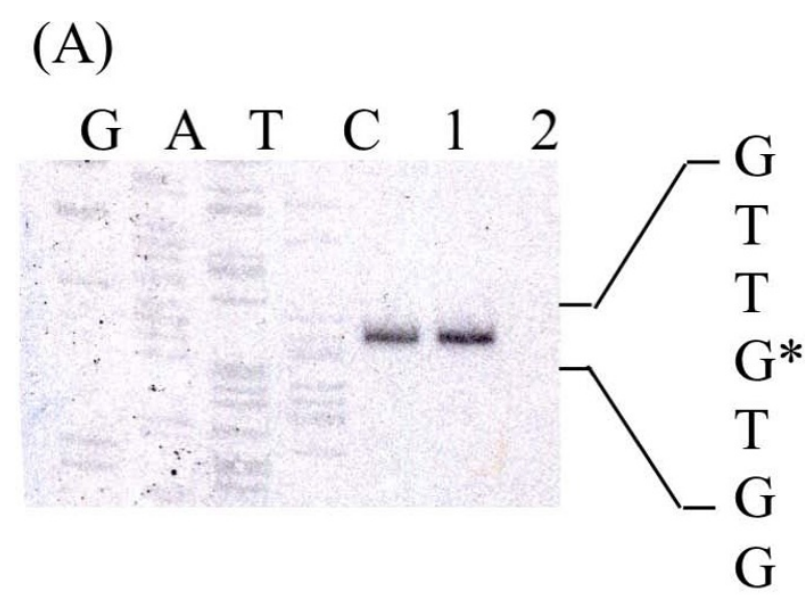

(B)

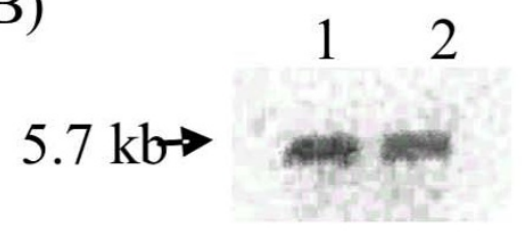

(C)

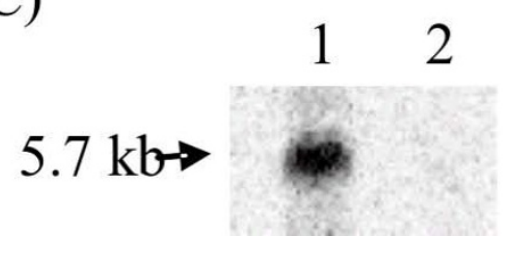

Figure 3

Transcriptional analysis of the $L$. plantarum cggR operon. (A) Primer extension products were obtained by using oligonucleotide cgg4 and total RNA extracted from $L M 3$ and $L M 3-C C I$. As a reference, sequencing reactions were performed with the same primer. Lanes: I, LM3; 2, LM3-CCl. Northern blot hybridization of total RNA extracted from LM3 and LM3-CCI with cggR (B) or enoAI (C) probes. Lanes: I, LM3; 2, LM3-CCI.

LM3-CC1 surface proteins, showed the presence of EnoA2 (Fig 4, panel B), while EnoA1 was not anymore detected.

Fn-overlay assay was performed on cell surface proteins extracted from wild type and LM3-CC1 cells (Fig. 5). A positive signal corresponding to a $40 \mathrm{kDa}$ Fn-binding protein was detected in cell surface protein extracts of both strains (Fig. 5, panel B), while the signal corresponding to the $48 \mathrm{kDa}$ adhesin, namely the EnoA1 protein, was detected only in the wild type strain. 
(A)

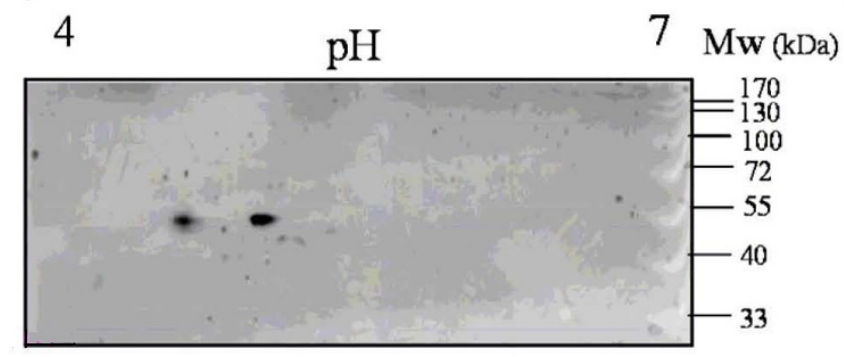

(B)

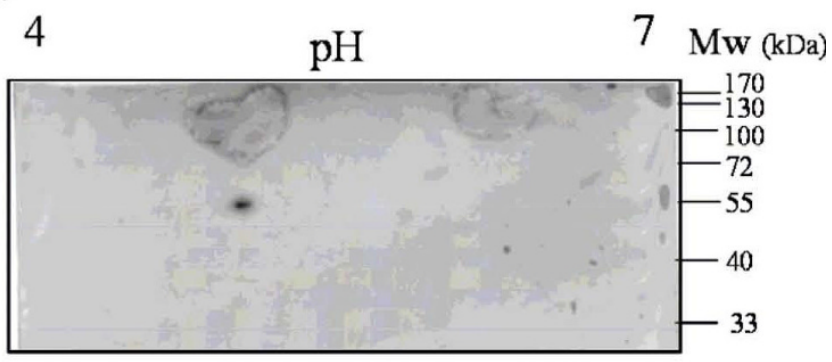

Figure 4

Western blot analysis of Lactobacillus plantarum LM3 (A) and LM3-CCI (B) surface proteins resolved in a twodimensional gel electrophoresis, and assayed with anti-streptococcal enolase antibody.

\section{Adhesion of wild type and mutant strains to immobilized fibronectin}

In order to prove the significance of the $48 \mathrm{kDa}$ surface protein for L. plantarum LM3 adhesion to fibronectin, the extent of binding of LM3 and LM3-CC1 cells was analyzed on Fn-coated microtiter plates. To verify if $\mathrm{pH}$ could affect the binding, experiments were repeated with bacteria cells pre-treated in Tris buffers at $\mathrm{pH}$ ranging from 5.0 to 7.0. Bacterial adhesion was evaluated by quantification of Fnbound cells by Real-time PCR, amplifying 16 S ribosomal DNA with species-specific primers [27]. A significant difference in adherence $(P<0.05)$ was observed, with about ten times more wild type than mutant cells adhering to fibronectin (Fig. 6). Nevertheless, no significant difference in adherence was found upon pre-treatment of both strains in different $\mathrm{pH}$ buffers.

\section{Discussion}

Microorganisms have developed different mechanisms to successfully colonize human tissues, in terms of either pathogenic or commensal type of interaction $[1,18]$. The

(A)

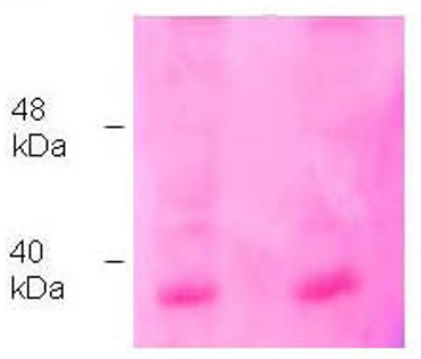

Figure 5

Fibronectin overlay assay performed on surface proteins of $L$. plantarum LM3 and LM3-CCI. (A) PVDF membrane stained with Ponceau S. (B). Autoradiography of PVDF membrane after peroxidase assay. Lanes: I, LM3; 2 , LM3-CCI. adhesion to host tissues represents a crucial early step in the colonization process, and bacterial pathogens usually express surface-bound adhesion molecules interacting with host receptors. For instance, in early stages of colonization, bacteria may use pili, fimbria and a variety of adhesins to interact with a plethora of different host elements displayed on the host cell surface, either membrane-bound or secreted, including ECM proteins. Among the ECM, the glycoprotein fibronectin was shown to be

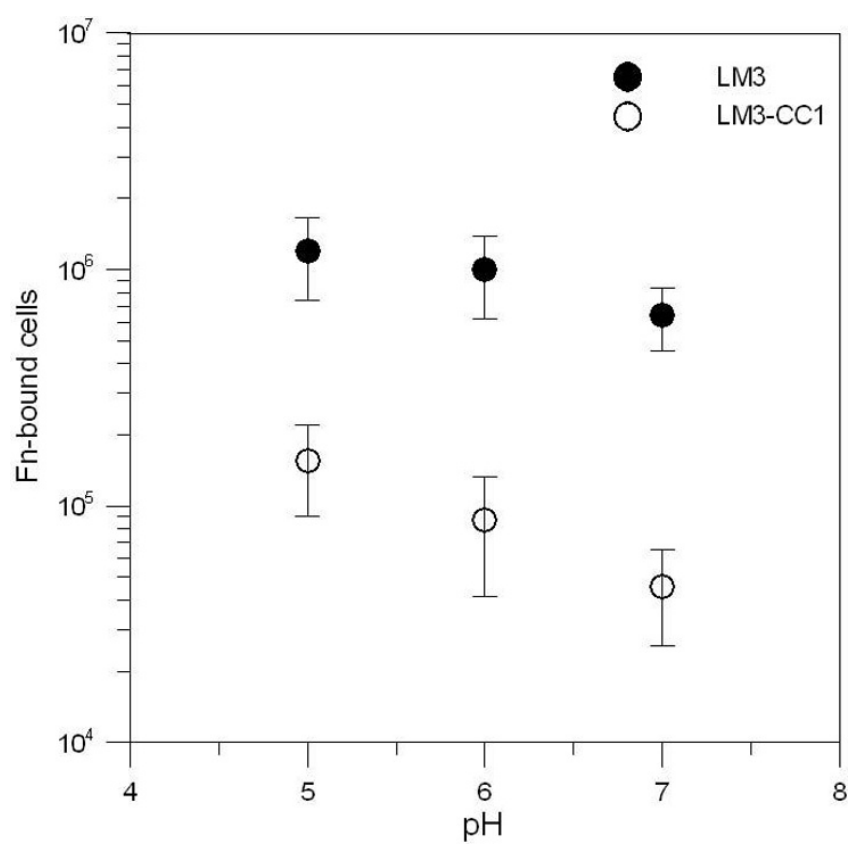

Figure 6

Binding of LM3 and LM3-CCI to fibronectin immobilized on microtiter plate wells. Adhesion of both strains was evaluated by Real-time PCR. Adhesion is given as number of bacteria bound to fibronectin at different values of $\mathrm{pH}$. Error bars represent \pm standard deviation of the mean values. 
the target for interaction with many pathogens as well as with some probiotic bacteria $[19,28-34]$. L. plantarum is a lactic acid bacterium often described as an inhabitant of the human intestinal tract. The probiotic features of some strains of L. plantarum have been extensively described. A mannose specific adhesion mechanism for interaction of L. plantarum 299 with human colonic cell line HT-29 was described many years ago [21], and more recently the identification of the mannose-specific adhesin was shown [23]. In this report we investigated L. plantarum fibronectin binding proteins. To this aim, we used the L. plantarum LM3 strain, which we classified as an adhesive strain on Caco-2 cell line according to Jacobsen and coworkers [25]. This strain was also previously classified as a mannose adhesive strain [23]. In particular, we describe the identification of a L. plantarum cell surface displayed protein, of apparent molecular mass of $48 \mathrm{kDa}$, which specifically binds to human fibronectin. By means of mass spectrometric analysis the $48 \mathrm{kDa}$ Fn-specific adhesin was identified as the EnoA1 alfa-enolase, encoded by the enoA1 gene. The cell surface localization of the protein was proved by immune electron microscopy using a polyclonal antibody generated against the Streptococcus pneumoniae alfa-enolase. Moonlighting proteins are defined as highly conserved cytoplasmatic proteins that, when expressed on the bacterial cell wall, acquire a "moonlighting" function different from their well-known activity performed in the cytoplasm. Moonlighting functions for many housekeeping enzymes, such as enolase, is now well documented, and some of these enzymes may act as virulence factor for pathogens [35,36]. Indeed, surface-displayed enolase of different pathogen bacteria binds to host glycoprotein: in Staphylococcus aureus alfa-enolase was shown to bind the ECM protein laminin [37]; surfacedisplayed enolase was demonstrated to bind to plasminogen in Streptococcus pneumoniae and Bacillus anthracis and to mucin and plasminogen in Streptococcus mutans [3840]. Moreover, surface-displayed enolase was demonstrated to bind to plasminogen also in bacterial species of the human indigenous microbiota $[41,42]$.

To assess the role of EnoA1 as a L. plantarum Fn-specific adhesin, we isolated the L. plantarum LM3-CC1 strain, carrying a null mutation in the enoA1 gene. Disruption of the eno gene was unsuccessful in S. pneumoniae, demonstrating that alfa-enolase is essential for viability of this microorganism [38]. The isolation of the LM3-CC1 mutant strain was planned upon the observation that in the $L$. plantarum WCFS1 genome, sharing high percent of sequence identity with the LM3 strain [26], the enoA2 gene, coding for EnoA2 alfa-enolase, is also present and is expressed under standard growth conditions (Muscariello, personal comunication). By Western blot analysis of cell surface proteins resolved on two dimensional gel, both alfa-enolases were detected in the wild type, while only EnoA2 was shown to be present in the LM3-CC1 surface protein extracts. Moreover, immunoblotting assays performed on the LM3-CC1 strain clearly demonstrated the lack of the Fn-specific EnoA1 adhesin. The characterization of the LM3-CC1 mutant strain shows that EnoA1 contributes significantly to adhesion to fibronectin. In fact the mutant strain adheres less efficiently than wild type strain to Fn-coated wells. Residual adhesion of LM3-CC1 is probably due to other adhesion molecules involved in the interaction bacteria-ECM proteins. The possibility of a comparative analysis between the LM3 wild type and LM3-CC1 mutant strain doubtless allows to assess the role of L. plantarum Eno A1 as a fibronectin binding protein.

\section{Conclusion}

We demonstrated the surface localization of the $L$. plantarum EnoA1 alfa-enolase, which specifically binds to human fibronectin, an extracellular matrix protein. In $L$. plantarum, the expression of two eno genes, as detected by microarray analysis, allowed the isolation of the LM3CC1 strain, carrying a null mutation in the enoA1 gene. Comparative analysis of the LM3 and LM3-CC1 surface proteins by anti-enolase Western blot, and by Fn-overlay immunoblotting assay, doubtless demonstrated the involvement of the EnoA1 protein in binding of $L$. plantarum to fibronectin. Moreover, by an adhesion assay we showed that LM3-CC1 cells bind to fibronectin-coated surfaces less efficiently than wild type cells. The isolation of the LM3-CC1 strain gave the possibility, for the first time to our knowledge, to quantitatively compare adhesion of wild type and mutant strain, thus demonstrating the significance of the surface displaced EnoA1 protein in the mechanism of adhesion to fibronectin.

\section{Materials and methods \\ Bacterial strains and culture conditions}

L. plantarum LM3 [43], L. plantarum LM3-CC1 (this study), and the Escherichia coli Top10 strains were used throughout this study. The L. plantarum strains were cultured at $30^{\circ} \mathrm{C}$ in MRS broth supplemented with either $0.5 \%$ or $2 \%$ glucose. The E. coli strain was grown at $37^{\circ} \mathrm{C}$ in TY broth. When needed, the following antibiotics were added: erythromycin 250 microgramms/ml for E. coli, and 5 microgramms/ml for L. plantarum; lincomycin 10 microgramms/ml for L. plantarum.

\section{SDS-PAGE and fibronectin overlay assay}

Surface proteins (10 microgramms), obtained by ultracentrifugation of French-pressed L. plantarum LM3 cells, were subjected to SDS-PAGE $(10 \%)$. The proteins were transferred to an Immun-Blot PVDF membrane (BIORAD Inc.) using the Mini Trans-Blot equipment (BIORAD Inc.), at $35 \mathrm{~V}, 4^{\circ} \mathrm{C}$, for $16 \mathrm{~h}$ in Towbin Buffer $(20 \mathrm{mM}$ Tris base, $192 \mathrm{mM}$ glycin, 20\% methanol, $\mathrm{pH}$ 8.3). The PVDF membrane was reversibly stained with Ponceau $S$ 
(Sigma). To detect fibronectin binding, overlay assays were performed as described [28] with some modifications: the PVDF membranes were incubated with blocking buffers I and II, washed with NN' buffer and overlaid with 0.2 microgramms $/ \mathrm{ml}$ of human fibronectin (CalbiochemOncogene) overnight at $4^{\circ} \mathrm{C}$. After three washes, primary antibody for fibronectin (anti-human IgG, mouse generated, Calbiochem-Oncogene), diluted 1:60000 in NN' buffer, was added and incubated at r.t. for $1 \mathrm{~h}$. The PVDF membranes were washed three times and incubated with a 1:5000 dilution of the secondary antibody conjugated with horseradish peroxidase (GE Healthcare), in blocking buffer, at r.t. for $1 \mathrm{~h}$. After three washes the bound antibodies were revealed with ECL PLUS kit (GE Healthcare).

\section{Protein identification by Peptide Mass Fingerprinting}

In-gel digestion was carried out according to Shevchenko and co-workers [44]. Briefly, selected Comassie-stained protein bands were excised from gels and destained with $50 \%$ acetonitrile (ACN) in $100 \mathrm{mM}$ ammonium bicarbonate, dehydrated in ACN and vacuum-dried in a SpeedVac centrifuge. Proteins contained in gel pieces were treated with $10 \mathrm{mM}$ dithiothreitol in $100 \mathrm{mM}$ ammonium bicarbonate at $56^{\circ} \mathrm{C}$ for $1 \mathrm{~h}$ to reduce disulphide bridges, and alkylation of the cysteine residues was carried out with $50 \mathrm{mM}$ iodoacetamide in $100 \mathrm{mM}$ ammonium bicarbonate at r.t. in the dark for $30 \mathrm{~min}$. Gel bands were dehydrated in ACN and re-swollen in $10 \mathrm{ml}$ of buffer solution ( $25 \mathrm{mM}$ ammonium bicarbonate $\mathrm{pH} 8.4)$ containing $10 \mathrm{ng} / \mathrm{ml}$ of trypsin at $4{ }^{\circ} \mathrm{C}$ for $15 \mathrm{~min}$. Excess of enzymatic solution was removed and $20 \mathrm{ml}$ of buffer solution were added to the gel pieces. Digestion proceeded overnight at $37^{\circ} \mathrm{C}$. The obtained peptide mixture $(0.5 \mathrm{ml})$ was mixed with $0.5 \mathrm{ml}$ of a saturated solution of alfa-cyano-4hydroxycinnaminic acid $[10 \mathrm{mg} / \mathrm{ml}$ in $50 \%$ ACN containing $25 \mathrm{fmol} / \mathrm{microliter}$ angiotensin and $125 \mathrm{fmol} / \mathrm{micro}-$ liter ACTH (Adrenocorticotropic Hormone fragment 1839) as internal standards], spotted directly on a MALDI target plate and dried under ambient condition. All mass spectra were generated on a MALDI-TOF mass spectrometer Voyager DE ${ }^{\text {TM }}$ PRO (Applied Biosystems), operating in positive-ion reflectron mode. The laser intensity $\left(\mathrm{N}_{2}, 337\right.$ $\mathrm{nm}$ ) was set just above the ion generation threshold and pulsed every $10 \mathrm{~ns}$. Mass spectra were acquired from each sample in the $700-3500 \mathrm{~m} / \mathrm{z}$ range, by accumulating 100 laser shots and were calibrated using as internal standards the monoisotopic peaks of angiotensin ( $\mathrm{m} / \mathrm{z}$ 931.5154) and ACTH (m/z 2465.1989). All mass values are reported as monoisotopic masses. Protein identification was achieved by using the MALDI mass spectral data for database searches against the NCBInr database using the MASCOT search algorithm http://www.matrixscience.com/. Parameters for all searches were as follows: bacteria as taxonomic category, trypsin as enzyme, carbamidomethyl as fixed modification for cysteine residues and methionine oxidation as variable modification, one missing cleavage and $30 \mathrm{ppm}$ as mass tolerance for the monoisotopic peptide masses.

\section{Resolution of Lactobacillus cell wall proteins by 2DE}

Five hundred micrograms (wet wt) of cell wall material, obtained by ultracentrifugation of French-pressed $L$. plantarum LM3 cells, was suspended in 100 micro-liters of $100 \mathrm{mM}$ Tris-HCl, pH 7.4, containing 1\% SDS and boiled for $10 \mathrm{~min}$. After cooling, 30 micro-liters solubilization buffer, consisting of $7 \mathrm{M}$ urea, $2 \mathrm{M}$ thiourea, $4 \%$ CHAPS, $1 \%$ DTT, $0.2 \%$ Bio-Lytes pH 3-10, and $0.002 \%$ bromophenol blue, was added. The mixture was gently agitated for $30 \mathrm{~min}$ at room temperature, followed by TCA precipitation. The cell wall fraction was solubilized in IEF solution containing $7 \mathrm{M}$ urea, $2 \mathrm{M}$ thiourea, 4\% CHAPS, $1 \%$ DTT, $1 \%$ Bio-lytes 3-10 and $0.002 \%$ bromophenol blue for two-dimensional polyacrylamide gel electrophoresis (2DE) analysis. Two-dimensional electrophoresis of extracted cell wall proteins was performed as follows; in the first dimension, isoelectrofocusing (IEF) was performed using the Bio-Rad PROTEAN IEF cell and Ready linear IPG strips (7 cm, pH 3-10). The IPG strips were hydrated overnight $(16 \mathrm{~h})$ with 2 micrograms of membrane protein and IEF was carried out at $500 \mathrm{~V}$, rapid mode, for $30 \mathrm{~min}, 1000 \mathrm{~V}$ for $30 \mathrm{~min}$, followed by gradient voltage to $8000 \mathrm{~V}$ in $30 \mathrm{~min}, 8000 \mathrm{~V}$ for $1 \mathrm{~h}, 50 \mathrm{~V}$ until stop. Prior to electrophoresis in the second dimension, IPG strips were thawed and incubated for $10 \mathrm{~min}$ in $2 \mathrm{ml}$ equilibration buffer containing $6 \mathrm{M}$ urea, $1,5 \mathrm{M}$ Tris- $\mathrm{HCl}$, pH $8.8,2 \%$ SDS, 20\% glycerol, and 2\% DTT, followed by incubation with equilibration buffer supplemented with $2.5 \%$ iodoacetamide for $10 \mathrm{~min}$ at room temperature. Second-dimensional $12 \%$ polyacrylamide gels were run at $160 \mathrm{~V}$ for $2.5 \mathrm{~h}$.

\section{Western blot analysis}

L. plantarum LM3 cell wall proteins (2 micrograms) were analyzed by $2 \mathrm{DE}$ as reported above and blotted onto a nitrocellulose membrane (Hybond ECL, Amersham), using the Mini Trans-Blot equipment (BioRad Inc.), at 90 $\mathrm{mA}, 4^{\circ} \mathrm{C}$, for $16 \mathrm{~h}$ in Towbin Buffer. The membrane was incubated in TBST buffer $(20 \mathrm{mM}$ Tris base, $137 \mathrm{mM}$ $\mathrm{NaCl}, 0.15 \%$ Tween 20 ) + nonfat dry milk $4 \%$ for $1 \mathrm{~h}$ at r.t., with orbital shaking, then incubated with anti-streptococcal enolase (IgG, rabbit generated), diluted 1:1000 in blocking buffer, at r.t. for $1 \mathrm{~h}$. After three washes with TBST the membrane was incubated with a 1:10000 dilution of the secondary antibody conjugated with horseradish peroxidase (GE Healthcare), in blocking buffer at r.t. for $1 \mathrm{~h}$. After three washes with TBST the bound antibodies were revealed with ECL PLUS kit (GE Healthcare). 


\section{Immune electron microscopy}

L. plantarum LM3 cells were grown in $10 \mathrm{ml}$ of MRS broth with $2 \%$ glucose up to stationary phase, centrifuged, washed three times with phosphate-buffered saline (PBS) buffer, and resuspended in the same buffer to a concentration of $10^{9}$ cells $/ \mathrm{ml}$. One $\mathrm{ml}$ of the cellular suspension was centrifuged and resuspended in 95 micro-liters of PBS with $1 \%$ bovine serum albumin (BSA). The anti-streptococcal enolase primary antibody, diluted 1:250 or 1:500, was added and incubated for $30 \mathrm{~min}$ at r.t with shaking. The cells were washed twice with PBS, added with $1 \%$ BSA, and incubated with 25 micro-liters of a 1:5 dilution of the secondary antibody conjugated with $10 \mathrm{~nm}$-colloidal gold particles (AuroProbe, Amersham), in PBS-BSA, for $30 \mathrm{~min}$ at r.t. with shaking. The cells were then washed with PBS-BSA; the last washing was performed with PBS only. The pellet was fixed for $4 \mathrm{~h}$ at $4{ }^{\circ} \mathrm{C}$ with $2.5 \%$ glutaraldehyde in $0.1 \mathrm{M}$ cacodylate buffer (CB) and washed overnight with $0.15 \mathrm{M} \mathrm{CB}$. The pellet was treated with $1 \%$ $\mathrm{OsO}_{4}$ in $0.1 \mathrm{M} \mathrm{CB}$ for $1 \mathrm{~h}$ at $4^{\circ} \mathrm{C}$, then washed twice in $0.15 \mathrm{M} \mathrm{CB}$. The pellet was treated with increasing alcohol concentrations $(30 \%, 50 \%, 70 \%, 96 \%, 100 \%)$, with propylene oxide, $2 / 3$ propylene oxide $+1 / 3$ Araldite $M$ resin, $1 / 3$ propylene oxide $+2 / 3$ resin, and embedded overnight in pure resin at $60^{\circ} \mathrm{C}$. The embedded pellet was cut with an ultramicrotome and the slices were observed with an electron microscope.

\section{Construction of a strain carrying a null mutation in the enoAl gene}

Based on the high percent of identity between the LM3 strain and the WCFS1 strain [26]. DNA fragments were amplified from the LM3 chromosome using the WCFS1 sequence data. The chromosomal DNA of L. plantarum LM3 was used as a template for two PCR reactions in order to amplify the two fragments UP (830 bp) and DOWN (930 bp). UP includes the tpiA gene and the first $109 \mathrm{bp}$ of the enoA1 gene. DOWN corresponds to the lp_0793 locus. In the PCR reaction the oligonucleotides eno1 (5'CGCGAATTCCCCAGCCCTTTTCTTACAGG-3') and eno2 (5'-CGCGGATCCCGATACCGCGGCCAAATGCG-3') were used to amplify the UP region, and eno5 (5'AAAACTGCAGGGAGCGAGCAGAATGGATGAC-3') and eno6 (5'-CCCAAGCTTGCAATGTGCGGCCGCTGTGC-3') were used to amplify the DOWN region. The UP and DOWN fragments were cloned, respectively, upstream and downstream of the ery cassette of pUC18Ery plasmid, in the EcoRI-BamHI and PstI-HindIII sites, yielding the pCV3 plasmid, used to transform L. plantarum as described [43].

\section{Primer extension and Northern blot analysis}

Total RNA from L. plantarum cells grown to mid-exponential phase on MRS medium supplemented with $2 \%$ glucose was isolated as described [43]. Primer extension products of $c g g R$ transcript were obtained by using oligonucleotide cgg4 (5'-CGACGACTCAGCATGTCAAC-3'). Northern blotting on total RNA extracted from cells grown on glucose, using 360- and 320-bp internal fragments of the $c g g R$ and enoA1 genes as probes, was performed as described [43].

\section{Adherence of bacteria to Fn-coated surfaces}

For adherence assays, Lactobacillus plantarum LM3 was grown in MRS broth with $0,5 \%$ glucose for $12 \mathrm{~h}$ at $30^{\circ} \mathrm{C}$. Cells were harvest by centrifugation at $3500 \mathrm{rpm}$ for 15 minutes at $4{ }^{\circ} \mathrm{C}$ for three times and the pellets were resuspended in $50 \mathrm{mM}$ Tris- $\mathrm{HCl}$ at $\mathrm{pH} 5,6,7,8$ and incubated at $30^{\circ} \mathrm{C}$ for $1 \mathrm{~h}$. Cells were harvest by centrifugation and resuspended in Dulbecco's modified Eagle's medium (DMEM) with $2 \%$ fetal bovine serum (FBS, Invitrogen).

Microtiter plates (96 wells) were coated overnight with fibronectin 0,25 micrograms/well at $4^{\circ} \mathrm{C}$ overnight and subsequently blocked with $2 \%$ BSA for $1 \mathrm{~h}$ at $37^{\circ} \mathrm{C}$. After three washes with PBST a 100 micro-liters bacterial suspension containing $5 \times 10^{7} \mathrm{CFU}$ in DMEM was added, and after $2 \mathrm{~h}$ of incubation at $37^{\circ} \mathrm{C}$ the wells were washed three times with PBST. Adherent bacteria were detached from the wells by adding 100 micro-liters of 10\% trypsin and quantified by real-time PCR. An aliquot of 20 microliters was transferred into a 0.2 ml-reaction tube and incubated for $10 \mathrm{~min}$ at room temperature with 3.8 micro-liters of trypsin inhibitor solution (Type I-S: from soybean, Sigma; $1 \mathrm{mg} / \mathrm{ml}$ in $\mathrm{H}_{2} \mathrm{O}$ ). The bacterial cells were specifically quantified by real-time PCR performed with speciesspecific primers: Bact-0011f (5'-AGAGTTTGATCATGGCTCAG-3') and Lab-0677r (5'-CACCGCTACACATGGAG-3') [27]. Real-time PCR was performed in a LightCycler instrument (Roche, Mannheim, Germany) and SYBER Green I fluorophore was used to correlate the amount of PCR product with the fluorescent signal. Amplification was carried out in a 20 micro-liters final volume containing 2 micro-liters of cell suspension, 0.5 micromolar of each primer and 4 micro-liters of LightCycler-FastStart DNA Master SYBR Green I (Roche). The experimental protocol consisted of the following programs: (i) starting preincubation at $95^{\circ} \mathrm{C}$ for $10 \mathrm{~min}$; (ii) amplification including 30 cycles of 4 steps each at the temperature transition time of $20^{\circ} \mathrm{C} / \mathrm{s}$ : denaturation at $95^{\circ} \mathrm{C}$ for $15 \mathrm{~s}$, annealing at $63^{\circ} \mathrm{C}$ for $25 \mathrm{~s}$, extension at $72^{\circ} \mathrm{C}$ for $30 \mathrm{~s}$, and fluorescence acquisition at $85^{\circ} \mathrm{C}$ for $5 \mathrm{~s}$; (iii) melting curve analysis: heating at $20^{\circ} \mathrm{C} / \mathrm{s}$ to $95^{\circ} \mathrm{C}$; cooling at $20^{\circ} \mathrm{C} / \mathrm{s}$ to $60^{\circ} \mathrm{C}$ with $15 \mathrm{~s}$ hold, and then heating $0.1^{\circ} \mathrm{C} / \mathrm{s}$ until $99^{\circ} \mathrm{C}$. As internal standards we amplified serial dilutions of the respective bacteria in PBS ranging from $2 \times$ $10^{6}$ to $2 \times 10^{3} \mathrm{CFU} / \alpha \mathrm{l}$.

\section{Competing interests}

The authors declare that they have no competing interests. 


\section{Authors' contributions}

CC and VV performed most of the experiments; RAS performed the MALDI-TOF analysis; MC performed the Western blot analysis with anti-streptococcal enolase; MV performed the immune electron microscopy; LM performed transcription analysis in the LM3-CC1 strain; RM contributed to experiment design and discussion; MS contributed in discussions during the work and in the preparation of the manuscript. All authors read and approved the final manuscript.

\section{Acknowledgements}

We thank Prof. Patrizia Brigidi (Università di Bologna, Italy) for helpful discussions and critical reading of the manuscript. This work was partially supported by the Progetto L.R. 05, Regione Campania, Italy.

\section{References}

I. Guarner F, Malagelada JR: Gut flora in health and disease. Lancet 2003, 360:5।2-519.

2. Backhed F, Ley RE, Sonnenburg JL, Peterson DA, Gordon JI: Host/ bacterial mutualism in the human intestine. Science 2005 , 307:1915-1920.

3. Zoetendal EG, Vaughan EE, de Vos WM: A microbial word within us. Mol Microbiol 2006, 59:1639-1650.

4. Ley RE, Peterson DA, Gordon Jl: Ecological and evolutionary forces shaping microbial diversity in the human intestine. Cell 2006, I 24:837-848.

5. Servin AL: Antagonistic activities of lactobacilli and bifidobacteria against microbial pathogens. FEMS Microbiol Rev 2004, 28:405-440.

6. Antikainen J, Kuparinen V, Lähteenmäki K, Korhonen TK: Enolases from Gram-positive bacterial pathogens and commensal lactobacilli share functional similarity in virulence-associated traits. FEMS Immunol Med Microbiol 2007, 5 I:526-534.

7. Falagas ME, Rafailidis PI, Makris GC: Bacterial interference for the prevention and treatment of infections. Int J Antimicrob Agents 2008, 3 I:5 I 8-522.

8. Cerutti A, Rescigno M: The biology of intestinal immunoglobulin A responses. Immunity 2008, 28:740-750.

9. Tsuji M, Suzuki K, Kinoshita K, Fagarasan S: Dynamic interactions between bacteria and immune cells leading to intestinal IgA sythesis. Semin Immunol 2008, 20:59-66.

10. Seegers JF: Lactobacilli as live vaccine delivery vectors: progress and prospects. TRENDS Biotechnol 2002, 20:508-5I5.

II. Daniel C, Repa A, Wild C, Pollak A, Pot B, Breiteneder H, Wiedermann $U$, Mercenier $A$ : Modulation of allergic immune responses by mucosal application of recombinant lactic acid bacteria producing the major birch pollen allergen Bet $\mathbf{v} \mathbf{I}$. Allergy 2006, 61:812-819.

12. Ahrnè S, Nobaek S, Jeppsson B, Adlerberth I, Wold AE, Molin G: The normal Lactobacillus flora of healthy human rectal and oral mucosa. J Appl Microbiol 1998, 85:88-94.

13. Molin G: Probiotics in foods not containing milk or milk constituents, with special reference to Lactobacillus plantarum 299v. Am J Clin Nutr 200I, 73:S380-385.

14. Klaenhammer TR, Azcarate-Peril MA, Altermann E, Barrangou R: Influence of the dairy environment on gene expression and substrate utilization in lactic acid bacteria. J Nutr 2007, 1 37:748S-750S.

15. Michail S, Abernathy F: Lactobacillus plantarum reduces the in vitro secretory response of intestinal epithelial cells to enteropathogenic Escherichia coli infection. J Pediatr Gastroenterol Nutr 2002, 35:350-355.

16. Goossens DA, Jonkers DM, Russel MG, Stobberingh EE, Stockbrugger RW: The effect of probiotic drink with Lactobacillus plantarum $299 \mathrm{v}$ on the bacterial composition in faeces and mucosal biopsies of rectum and ascending colon. Aliment Pharmacol Ther 2006, 23:255-263.

17. Kinoshita H, Uchida H, Kawai Y, Kitazawa H, Miura K, Shiiba K, Horii A, Saito T: Quantitative evaluation of adhesion of lactobacilli isolated from human intestinal tissues to human colonic mucin using surface plasmon resonance. J Appl Microbiol 2007, 102:116-123.

18. Pizarro-Cerdà J, Cossart P: Bacterial adhesion and entry into host cells. Cell 2006, I 24:7| 5-727.

19. Buck BL, Altermann E, Svingerud T, Klaenhammer TR: Functional analysis of putative adhesion factors in Lactobacillus acidophilus NCFM. Appl Environ Microbiol 2005, 7 I:8344-835I.

20. Boesten RJ, de Vos WM: Interactomics in the human intestine: Lactobacilli and Bifidobacteria make a difference. J Clin Gastroenterol 2008, 42: 163-167.

21. Adlerberth I, Ahrnè S, Johansson M, Molin G, Hanson L, Wold AE: A mannose-specific adherence mechanism in Lactobacillus plantarum conferring binding to the human colonic cell line HT-29. Appl Environ Microbiol 1996, 62:2244-225I.

22. Tallon R, Arias S, Bressolier P, Urdaci MC: Strain- and matrixdependent adhesion of Lactobacillus plantarum is mediated by proteinaceous bacterial compounds. J Appl Microbiol 2007, I 02:442-45I.

23. Pretzer G, Snel J, Molenaar D, Wiersma A, Bron PA, Lambert J, de Vos WM, Meer R van der, Smits MA, Kleerebezem M: Biodiversitybased identification and functional characterization of the mannose-specific adhesin of Lactobacillus plantarum. J Bacteriol 2005, 187:6128-6136.

24. Kleerebezem M, Boekhorst J, van Kranenburg R, Molenaar D, Kuipers OP, Leer R, Targhini R, Peters SA, Sandbrink HM, Fiers MW, Stiekema W, Lankhorst RM, Bron PA, Hoffer SM, Groot MN, Kerkhoven R, de Vries M, Ursing B, de Vos WM, Siezen J: Complete genome sequence of Lactobacillus plantarum strain WCFS I. Proc Natl Acad Sci USA 2003, 100:1990-95.

25. Jacobsen CN, Rosenfeldt NV, Hayford AE, Moller PL, Michaelsen KF, Paerregaard A, Sandstrom B, Tvede M, Jakobsen M: Screening of probiotic activities of forty-seven strains of Lactobacillus spp. by in vitro techniques and evaluation of the colonization ability of five selected strains in humans. Appl Environ Microbiol 1999. 65:4949-4956.

26. Siezen R, Boekhorst J, Muscariello L, Molenaar D, Renckens B, Kleerebezem M: Lactobacillus plantarum gene clusters encoding putative cell-surface protein complexes for carbohydrate utilization are conserved in specific gram-positive bacteria. BMC Genomics 2006, 7:126-139.

27. Heilig HG, Zoetendal EG, Vaughan EE, Marteau P, Akkermans AD, de Vos WM: Molecular diversity of Lactobacillus spp. and other lactic acid bacteria in the human intestine as determined by specific amplification of $16 \mathrm{~S}$ ribosomal DNA. Appl Environ Microbiol 2002, 68: I| 4-123.

28. Lorca G, Torino MI, Font de Valdez G, Ljungh A: Lactobacilli express cell surface proteins which mediate binding of immobilized collagen and fibronectin. FEMS Microbiol Lett 2002, 206:3I-37.

29. Bisno AL, Brito MO, Collins CM: Molecular basis of group A streptococcal virulence. Lancet Infect Dis 2003, 3:191-200.

30. Schwartz-Linek $U$, Hook M, Potts RJ: The molecular basis of fibronectin-mediated bacterial adherence to host cells. Mol Microbiol 2004, 52:63 I-64I.

31. Nitsche-Schmitz DP, Rohde M, Chhatwal GS: Invasion mechanisms of Gram positive pathogenic cocci. Thromb Haemost 2007, 98:488-496.

32. Farfan MJ, Inman KG, Nataro JP: The major pilin subunit of the AAF/II fimbriae from enteroaggregative Escherichia coli mediates binding to extracellular matrix proteins. Infect Immun 2008, 76:4378-4384.

33. Leduc I, White CD, Nepuev I, Throm RE, Spinola SM, Elkins C: Outer membrane protein DsrA is the major fibronectin-binding determinant of Haemophilus ducreyi. Infect Immun 2008, 76:1608-1616.

34. Muñoz-Provencio D, Llopis M, Antolín M, de Torres I, Guarner F, Pérez-Martínez G, Monedero V: Adhesion properties of Lactobacillus casei strains to resected intestinal fragments and components of the extracellular matrix. Arch Microbiol 2009, 191(2):|53-6I. Epub 2008 Oct $3 \mid$

35. Copley SD: Enzymes with extra talents: moonlighting functions and catalytic promiscuity. Curr Opin Chem Biol 2003, 7:265-272.

36. Pancholi V, Chhatwal GS: Housekeeping enzymes as virulence factors for pathogens. Int J Med Microbiol 2003, 293:391-40I. 
37. Carneiro CR, Postol E, Nomizo R, Reis LF, Brentani RR: Identification of enolase as a laminin-binding protein on the surface of Staphylococcus aureus. Microb Infect 2004, 6:604-608.

38. Bergmann S, Rohde M, Chhatwal GS, Hammerschmidt S: alfa-enolase of Streptococcus pneumoniae is a plasmin(ogen)-binding protein displayed on the bacterial cell surface. Mol Microbiol 200I, 40: I 273-I 287.

39. Ge J, Catt DM, Gregory RL: Streptococcus mutans surface $\alpha$-enolase binds salivary mucin MG2 and human plasminogen. Infect Immun 2004, 72:6748-6752.

40. Agarwal S, Kulshreshtha P, Bambah Mukku D, Bhatnagar R: alphaEnolase binds to human plasminogen on the surface of Bacillus anthracis. Biochim Biophys Acta 2008, 1784:986-994.

4I. Candela M, Bergman S, Vici M, Vitali B, Turroni S, Eikmanns BJ, Hammerschmidt S, Brigidi P: Binding of human plasminogen to Bifidobacterium. J Bacteriol 2007, I89:5929-5936.

42. Hurmalainen V, Edelman S, Antikainen J, Baumann M, Lahteenmaki K, Korhonen TK: Extracellular proteins of Lactobacillus crispatus enhance activation of human plasminogen. Microbiol 2007, I53: | I |2-I I 22.

43. Muscariello L, Marasco R, De Felice M, Sacco M: The functional ccpA gene is required for carbon catabolite repression in Lactobacillus plantarum. Appl Environ Microbiol 200I, 67:2903-2907.

44. Shevchenko A, Chernushevich I, Ens W, Standing KG, Thomson B, Wilm B, Mann M: Rapid 'de novo' peptide sequencing by a combination of nanoelectrospray, isotopic labeling and a quadrupole/time-of-flight mass spectrometer. Rapid Commun Mass Spectrom 1997, I I:1015-1024.

Publish with Bio Med Central and every scientist can read your work free of charge

"BioMed Central will be the most significant development for disseminating the results of biomedical research in our lifetime. "

Sir Paul Nurse, Cancer Research UK

Your research papers will be:

- available free of charge to the entire biomedical community

- peer reviewed and published immediately upon acceptance

- cited in PubMed and archived on PubMed Central

- yours - you keep the copyright

Submit your manuscript here:

http://www.biomedcentral.com/info/publishing_adv.asp
BioMedcentral 